\title{
Reply to the comment on: 'Anxiogenic-like effects of chronic cannabidiol administration in rats' (Elbatsh MM, Assareh N, Marsden CA and Kendall DA; Psychopharmacology 2012)
}

\author{
Maha Mohamed Elbatsh • Neda Assareh • \\ Charles A. Marsden • David A. Kendall
}

Received: 10 May 2012 / Accepted: 11 June 2012 / Published online: 4 July 2012

(C) Springer-Verlag 2012

In reply to Dr. Gururajan's comments on our manuscript (Elbatsh et al. 2012) about the anxiogenic-like effects of chronic cannabidiol administration in rats, we accept that the use of a wider ranging dose/response design would have been desirable. We emphasised the need for additional longterm multi-dose studies of the drug in models of affective disease in the discussion which present constraints of finance and time have not allowed. Moreover, given that cannabidiol (CBD) is being reported almost as a panacea, we consider it of value to show, even if only at a single dose, that $\mathrm{CBD}$ can provoke potentially deleterious behavioural responses.

Secondly, in terms of the behavioural changes in the context of anxiety, not only total distance travelled was reported in the activity boxes, but also rearing and grooming as possible markers of anxiety-related behaviour. Locomotor activity in a neutral environment was measured to detect any hypoactivity associated with CBD treatment that could have interfered with the interpretation of behavioural changes in the conditioned emotional response (CER).
We used the CER test which had previously been used to show anxiolytic effects of acute CBD (Bitencourt et al. 2008; Resstel et al. 2006), but we agree that the elevated plus maze could also be an appropriate test, given that it would be useful to find converging effects in a number of anxiety test procedures.

Maha Elbatsh for the authors

\section{References}

Bitencourt RM, Pamplona FA, Takahashi RN (2008) Facilitation of contextual fear memory extinction and anti-anxiogenic effects of AM404 and cannabidiol in conditioned rats. Eur Neuropsychopharmacol 18:849-859

ElBatsh MM, Assareh N, Marsden CA, Kendall DA (2012) Anxiogeniclike effects of chronic cannabidiol administration in rats. Psychopharmacology (Berl) 221:239-247

Resstel LBM, Joca SRL, Moreira FA, Correa FMA, Guimaraes FS (2006) Effects of cannabidiol and diazepam on behavioural and cardiovascular responses induced by contextual conditioned fear in rats. Behav Brain Res 172:294-298

\footnotetext{
M. M. Elbatsh $(\bowtie)$

Faculty of Medicine, Clinical Pharmacology Department,

Menoufia University,

Shebin Elkom, Egypt

e-mail: maha.ali@med.menofia.edu.eg

N. Assareh · C. A. Marsden • D. A. Kendall

School of Biomedical Sciences, The University of Nottingham,

Nottingham, United Kingdom
} 